\title{
Refractive outcome following diode laser versus cryotherapy for eyes with retinopathy of prematurity
}

\author{
Kais Algawi, Michael Goggin, Michael O’Keefe
}

\begin{abstract}
The refractive error in $\mathbf{1 5}$ eyes with threshold retinopathy of prematurity treated with diode laser photocoagulation was compared with 25 eyes with the same disease severity treated by cryotherapy. Myopia was present in $\mathbf{4 0 \%}$ (six eyes) of the first group ranging from -1.50 to -3.50 dioptres, while $92 \%$ (23 eyes) showed myopia which ranged from -0.50 to -8.00 dioptres in the cryotherapy group. Sixty per cent (nine eyes) were hypermetropic at less than +3.0 dioptres in the laser group, while only $8 \%$ (two eyes) of the cryotherapy group showed hypermetropia. There was no significant difference in astigmatism between the two groups. Eyes with threshold disease treated with diode laser photocoagulation developed significantly less myopia than those treated with cryotherapy ( $p=0 \cdot 0006$, two tailed value). (Brf Ophthalmol 1994; 78: 612-614)
\end{abstract}

Retinopathy of prematurity (ROP) is the cause of blindness in $11 \%$ of blind children in the Republic of Ireland.' The high survival rate of premature infants means an increasing number of cases of ROP every year. Management of this problem, whether in the form of prophylaxis or as an active treatment of established disease, is a matter of great concern to ophthalmologists.

Xenon arc photocoagulation for ROP was reported in $1970^{2}$ and cryopexy in 1972 by Yamashita. $^{3}$ The reports of the CRYO-ROP Cooperative Group have contributed significantly towards the management of ROP. Their study has demonstrated the effectiveness of cryotherapy for 'threshold' disease. ${ }^{4}$

Laser photocoagulation for ROP has emerged as an effective alternative to cryopexy. Landers et al reported that eyes treated for ROP stage 3 threshold by argon laser photocoagulation (treating the avascular retina) showed favourable outcome in $73 \% .^{5}$ These favourable results were confirmed by Preslan. ${ }^{6}$ Diode laser has been shown to achieve similar results. ${ }^{7}$ Prematurity and low birth weight have long been known to be associated with myopia ${ }^{89}$ Retinopathy of prematurity increases the incidence of myopia. ${ }^{910}$

This study examines the refractive outcome in patients treated with diode laser and compares it with those treated with cryotherapy.

Ophthalmology, The

Temple Street, Dublin 1 Republic of Ireland K Algawi

M Goggin

M O'Keefe

Correspondence to: Mr Michael O'Keefe.

Accepted for publication 26 April 1994 Materials and methods
Thirty two premature infants ( 15 females and 17 males) with threshold ROP (stage $3+$ disease of 5 or more contiguous clock hours [ $30^{\circ}$ sectors] or 8 ment by diode laser or cryopexy. (In view of the known asymmetrical nature of the disease, eyes instead of patients are studied.)

The laser group consisted of 21 eyes of 12 infants who received diode laser retinal photocoagulation in the period between February and November 1992 using the Iris OcuLight SL diode laser system. Postnatal age, when refraction was done, ranged from 8 to 15 months (mean 13 months). Gestational ages of this group ranged from 24 to 32 weeks. The birth weight range was 700 to $1200 \mathrm{~g}$.

The cryotherapy group consisted of 32 eyes of 20 infants who were treated by cryopexy of the avascular retina in the period between January 1989 and February 1992. Gestational age ranged from 25 to 30 weeks with a birthweight range of 620 to $1500 \mathrm{~g}$.

The indications and methods of treatment of both groups are described elsewhere. ${ }^{711}$ Visual functions were assessed by either fixation pattern or preferential looking technique. Manual refraction was performed after the installation of cyclopentolate $0.5 \%$ and phenylephrine $2.5 \%$ eye drops in all patients. The refraction at 1 year of postnatal age of the cryotherapy group was used for comparison. Statistical analysis was performed by using the EPI INFO program and comparison of proportions was done by using the Fisher exact method. A figure of $<0.05$ is regarded as statistically significant.

\section{Results}

Fifty three eyes were treated; 21 received laser and 32 cryotherapy. Three eyes in the laser group were at or beyond stage 4, one eye progressed to total retinal detachment with difficult refraction, and two eyes of one patient who died before full post treatment assessment were excluded from this group, leaving 15 eyes for analysis. Five eyes in the cryotherapy group were at or beyond stage 4 and two other eyes had progressed to total retinal detachment, making refraction impossible; these seven eyes were excluded, leaving 25 eyes in this group.

In the laser group six eyes (40\%) showed myopia with a spherical equivalent of less than or equal to $-3 \cdot 50$ dioptres; nine eyes were hypermetropic with a spherical equivalent less than or equal to $+2 \cdot 50$ dioptres; five eyes showed significant astigmatism of less than or equal to 0.75 dioptre; and none had more than $3 \cdot 0$ dioptres of astigmatism (Table 1).

In the cryotherapy group 23 eyes (92\%) cumulative clock hours) or more, received treat-

showed myopia, 12 of which were less than or equal to -3.0 dioptres; seven were between -3.25 and -6.0 dioptres; and five eyes had 
Table 1 The extent of retinopathy of prematurity when first treated, refraction (in spherical equivalent), and retinal outcome in the laser group (all treated eyes had stage $3+$ plus disease)

\begin{tabular}{|c|c|c|c|}
\hline No & $\begin{array}{l}\text { Extent } \\
\text { (clock hours) }\end{array}$ & $\begin{array}{l}\text { Refraction } \\
\text { (spherical } \\
\text { equivalent) }\end{array}$ & Retinal outcome \\
\hline 11 & 6 & -0.625 & flat, scars \\
\hline 12 & 6 & -0.625 & flat, scars \\
\hline 13 & 5 & $+2 \cdot 50$ & flat, scars, pale disc \\
\hline 14 & 12 & $+1 \cdot 00$ & flat, scars, pale disc \\
\hline 17 & 6 & +1.75 & flat, scars \\
\hline 21 & 8 & -1.625 & flat, scars \\
\hline 24 & 12 & $+2 \cdot 00$ & flat, scars \\
\hline 25 & 12 & $+2 \cdot 00$ & flat, scars \\
\hline 44 & 8 & +1.75 & flat, scars \\
\hline 45 & 9 & $-3 \cdot 50$ & flat, scars \\
\hline 48 & 5 & $+1 \cdot 50$ & flat, scars \\
\hline 49 & 5 & $+1 \cdot 50$ & flat, scars \\
\hline 50 & 12 & $-3 \cdot 50$ & $\begin{array}{l}\text { flat, scars, dragged } \\
\text { disc }\end{array}$ \\
\hline 52 & 8 & $-1 \cdot 50$ & $\begin{array}{l}\text { flat, scars, localised } \\
\text { detachment }\end{array}$ \\
\hline 53 & 5 & $+2 \cdot 25$ & flat, scars \\
\hline
\end{tabular}

greater than or equal to $-6 \cdot 25$ dioptres (spherical equivalent). Only two eyes (8\%) showed hypermetropia and five eyes had significant astigmatism (Table 2).

Myopia was encountered significantly less in the laser group than the cryotherapy group $(\mathrm{p}=0.0006$, two tailed value). Conversely hypermetropia was noticed more in the laser group ( $p=0.0006$, two tailed value).

Astigmatic refractive errors did not show any significant difference between the two groups $(p=0 \cdot 4)$. Two eyes of one patient had lensectomies for infantile cataract; vitreoretinal surgery was carried out in the left eye with the final outcome of partial retinal detachment and perception of light only, while the right eye developed total retinal detachment with no light perception. Details of diode laser retinal photocoagulation and retinal cryotherapy for the treatment of these ROP patients are discussed elsewhere. $^{711}$

\section{Discussion}

The incidence of myopia in premature infants

Table 2 The extent of retinopathy of prematurity when first treated, refraction (in spherical equivalent), and retinal outcome in the cryotherapy group (all treated eyes had stage 3 + plus disease)

\begin{tabular}{|c|c|c|c|}
\hline No & $\begin{array}{l}\text { Extent } \\
\text { (clock } \\
\text { hours) }\end{array}$ & $\begin{array}{l}\text { Refraction } \\
\text { (spherical } \\
\text { equivalent) }\end{array}$ & Retinal outcome \\
\hline $\begin{array}{l}1 \\
2 \\
3 \\
4 \\
5 \\
6 \\
7 \\
10 \\
16 \\
18 \\
19 \\
20 \\
28 \\
29 \\
30 \\
31 \\
33 \\
34 \\
35 \\
36 \\
37 \\
38 \\
42 \\
43 \\
51\end{array}$ & $\begin{array}{r}6 \\
8 \\
12 \\
12 \\
12 \\
5 \\
12 \\
6 \\
9 \\
8 \\
12 \\
12 \\
12 \\
12 \\
12 \\
12 \\
12 \\
12 \\
12 \\
8 \\
9 \\
9 \\
6 \\
9 \\
8\end{array}$ & $\begin{array}{l}-6 \cdot 00 \\
-6 \cdot 75 \\
-4 \cdot 00 \\
-4 \cdot 00 \\
-2 \cdot 00 \\
+2 \cdot 00 \\
-1 \cdot 375 \\
+2 \cdot 00 \\
-8 \cdot 00 \\
-2 \cdot 50 \\
-2 \cdot 00 \\
-0 \cdot 50 \\
-1 \cdot 25 \\
-1 \cdot 25 \\
-3 \cdot 00 \\
-3 \cdot 00 \\
-5 \cdot 00 \\
-6 \cdot 00 \\
-4 \cdot 00 \\
-2 \cdot 75 \\
-8 \cdot 00 \\
-8 \cdot 00 \\
-3 \cdot 00 \\
-3 \cdot 00 \\
-6 \cdot 25\end{array}$ & $\begin{array}{l}\text { flat, scars } \\
\text { flat, scars } \\
\text { flat, scars } \\
\text { flat, scars } \\
\text { flat, scars } \\
\text { flat, scars } \\
\text { flat, scars } \\
\text { flat, scars } \\
\text { flat, scars, ONH } \\
\text { flat, scars } \\
\text { flat, scars } \\
\text { flat, scars } \\
\text { flat, scars } \\
\text { flat, scars } \\
\text { flat, scars } \\
\text { flat, scars, pale disc } \\
\text { flat, scars, ONH } \\
\text { flat, scars, ONH } \\
\text { flat, scars } \\
\text { flat, scars } \\
\text { flat, scars } \\
\text { flat, scars } \\
\text { subtotal retinal detachment } \\
\text { total retinal detachment } \\
\text { flat, dragged disc }\end{array}$ \\
\hline
\end{tabular}

$\mathrm{ONH}=$ optic nerve hypoplasia and its severity correlated positively with the severity of ROP and cicatrisation. ${ }^{9}$ Zaharias et al demonstrated that eyes affected with ROP were most often myopic; they also correlated myopia and its degree with the severity of the early retinal changes during the active phase of ROP, as well as with the cicatrisation phase. ${ }^{12}$

No significant statistical difference in degree of myopia was found between ROP eyes treated with cryopexy and those without. ${ }^{13}$ This was confirmed by Seiberth et al. ${ }^{14}$ Argon and diode laser treatment for ROP has resulted in a favourable outcome. ${ }^{57}$ The advantages of laser treatment for ROP when compared with cryotherapy include the fact that laser treatment of delicate fibrovascular tissues might lessen the haemorrhagic complications often associated with cryotherapy. Despite the fact that intense diode laser burns cause full thickness choroidal involvement and even thermal injury to the inner scleras of rabbit's eyes, ${ }^{15}$ it seems that these injuries are less extensive than those produced by cryotherapy. The creation of large areas of scarring by cryopexy may lead to the development of rhegmatogenous retinal detachment years after treatment. ${ }^{16}$

Indirect ophthalmoscope laser applications to the retina cause minimal conjunctival chemosis and subconjunctival haemorrhage. ${ }^{7}$ Diode laser in particular may have the following added advantages: its 'near' infrared emission wavelength of $810 \mathrm{~nm}$ has theoretically superior transmission properties through haemorrhage compared with argon laser; high energy conversion efficiency, which means lower power supply needed for its operation (standard household current or batteries) making it light and portable ${ }^{1718}$ and allowing treatment in the neonatal intensive care unit.

Diode laser hardware is less expensive than argon laser hardware. ${ }^{17}{ }^{18}$ On the other hand the drawbacks of laser treatment are the requirement of clear optical media for proper treatment, and haemorrhage, small pupils, and prominent tunica vasculosum lentis can limit the treatment. There are reports of accidental corneal and iris burns by indirect laser delivery system, ${ }^{19}$ though corneal burns were not experimentally reproducible. ${ }^{15}$

The high percentage of eyes with myopia by comparison with other reports in the cryotherapy group may be explained by the fact that all the eyes studied had stage $3+$ disease, whereas other reports of myopia and ROP did not specifically study eyes with advanced stages of ROP. ${ }^{8-10}$ Myopia occurs more frequently with prematurity, low birth weight, ROP, and visual deprivation. ${ }^{892021}$ Gordon and Donzis analysed the components of refractive errors in 10 eyes with myopia and ROP. These eyes showed lenticular and axial myopia, though only the high lens powers were found to be statistically significant compared with a control group. ${ }^{22}$ Christensen and Wallman looked at the scleras of visually deprived chicks and their findings suggested increase in the size and weight of the scleras by cell proliferation and increased synthesis of extracellular matrix. ${ }^{21}$ Fielder et al suggested that myopia of prematurity may be due to failure of flattening the usually steep intra- 
uterine cornea, ${ }^{23}$ while Majima and Hibino et al suggested that myopia is due to combination of increased axial length and lenticular thickness. ${ }^{2425}$ Fledelius has highlighted myopia of prematurity as a change which usually disappears with time and cautioned against confusing it with that associated with ROP. ${ }^{26}$ We find it quite difficult to differentiate between the two types of myopia at this stage.

Stone et al observed reduced concentrations of dopamine and its metabolites in myopic eyes compared with controls. ${ }^{27}$ These studies may give some insight into the association of myopia and ROP, but cannot explain the reason behind the reduced incidence of myopia in the laser group in our series. It is unlikely that cryopexy alone is the cause as Seiberth $e t a l^{14}$ and Teller et $a l^{13}$ found no significant difference in myopia between cryotreated and untreated eyes. This makes our findings all the more interesting.

We speculate that ablating the avascular retina with diode laser destroys the source of the possible 'chemical mediators of myopic changes' with minimal scleral damage that can influence the size of the eye that subsequently develops myopia.

It must be stated that our results are based on only a 1 year follow up for children who had laser therapy and our numbers are small. We feel that this early finding should be highlighted, but the longer follow up will be more interesting. In conclusion, myopia is a major complication in children with $\operatorname{ROP}^{912}{ }^{28}$ and any treatment that significantly reduces this complication will have major longer term benefit.

1 Goggin M, O'Keefe M. Childhood blindness in the Republic of Ireland - a national survey. Br f Ophthalmol 1991; 75: $425-9$

2 Nagata $M$. Treatment of acute proliferative retrolental fibroplasia with xenon are photocoagulation: its indications and limitation. Fpn $\mathcal{F}$ Ophthalmol 1970; 21: 435-59.

3 Yamashita Y. Studies on retinopathy of prematurity. III: Cryocautery for retinopathy of prematurity. $7 p n \mathcal{F}$ Clin Ophthalmol 1972; 26:385-93.

4 Cryotherapy for Retinopathy of Prematurity Cooperative Group. Multicentric trial of cryotherapy for retinopathy of prematurity: preliminary results. Arch Ophthalmol 1988; 106: 471-9.

5 Landers MB, Toth CA, Semple HC, Morse LS. Treatment of retinopathy of prematurity with argon laser photocoagulation. Arch Ophthalmol 1992; 110: 44-7.
6 Preslan MW. Laser therapy for retinopathy of prematurity. F Pediatr Ophthalmol Strabismus 1993; 30: 80-3.

7 Goggin M, O'Keefe M. Diode laser for retinopathy of prematurity - early outcome. Brf Ophthalmol 1993; 77: 559-62.

8 Quinn GE, Dobson V, Repka MX, Reynolds J, Kivlin J. Development of myopia in infants with birth weight less Development of myopia in infants with birth weight less
than 1251 grams. The Cryotherapy for Retinopathy of than 1251 grams. The Cryotherapy for Retinopathy of Prematurity

9 Nissenkorn I, Yassur Y, Mashkowski D, Sherf I, Ben-Sira I Myopia in premature babies with and without retinopathy of prematurity. Brf Ophthalmol 1983; 67: 170-3

10 Snir M, Nissenkorn I, Sherf I, Cohen S, Ben-Sira I. Visual acuity, strabismus and amblyopia in premature babies with and without retinopathy of prematurity. Ann Ophthalmol 1988; 20: 256-8.

11 Robinson R, O'Keefe M. Cryotherapy for retinopathy of prematurity - a prospective study. Brf Ophthalmol 1992; 76: 289-91.

12 Zaharias L, Chrisholm VF, Chapman RB. Visual and ocular damage in retrolental fibroplasia. Am $\mathcal{F}$ Ophthalmol 1962; 53 : $337-45$.

13 Teller J, Nissenkorn I, Ben-Sira I, Abraham FA. Ocular dimensions following cryotherapy for active stage of retinopathy of prematurity. Metabolic, Pediatric and Systemic Ophthalmology 1988; 11: 81-2.

14 Seiberth V, Knorz MC, Trinkmann R. Refractive errors after cryotherapy in retinopathy of prematurity. Ophthalmologica 1990; 201: 5-8.

15 Benner JD, Huang M, Morse LS, Hijelmeland LM, Landers $M B$. Comparison of photocoagulation with argon, crypton and diode laser indirect ophthalmoscope in rabbit eyes. Ophthalmology 1992; 99: 1554-63.

16 Greven CM, Tasman W. Rhegmatogenous retinal detachment following cryotherapy in retinopathy of prematurity. Arch Ophthalmol 1989; 107: 1017-8.

17 Hernquist KG. Long-pulse operation of argon lasers. Applied Optics 1970; 9: 2247-9.

18 Balles MW, Puliafito CA. Semiconductor diode lasers: a new light source in ophthalmology. Int Ophthalmol Clin 1990; 30: $77-83$.

19 Irvine WD, Smiddy WE, Nicholson DH. Corneal and iris burns with the laser indirect ophthalmoscope. [Letter.] Am F Ophthalmol 1990; 110: 311-3.

20 Birge HL. Myopia caused by prematurity. Am $\mathcal{f}$ Ophthalmol 1956; 41: 492-8.

21 Christensen AM, Walman J. Evidence that increased scleral growth underlines visual deprivation myopia in chicks. Invest Ophthalmol Vis $S$ ci 1991; 32: 2143-50.

22 Gordon RA, Donzis PB. Myopic association with retinopathy of prematurity. Ophthalmology 1986; 93: 1593-8.

23 Fielder AR, Levene MI, Russell IM, Weala RA. Temperature - a factor in ocular development? Dev Med Child Neurol 1986; $28: 279-84$.

24 Majima A. Studies on retinopathy of prematurity. II. Fundus appearance and ocular functions in cicatricial phase of very
low birth weight infants. Fpn f Ophthalmol 1977; 21:421-35.

25 Hibino Y, Takahashi M, Majima A. Studies on ocular functions of cicatricial retinopathy of prematurity. Measurements of refractive elements. $\mathcal{F}$ p $\mathcal{F}$ Clin Ophthalmol 1978; 32: 655-62.

26 Fledelius HC. Pre-term delivery and the growth of the eye. An oculometric study of eye size around term-time. Acta Ophthalmol 1992; 204 (Suppl): 10-5.

27 Stone RA, Lin T, Laties AM, Iuvone PM. Retinal dopamine and form-deprivation myopia. Proc Natl Acad Sci USA 1989; 86: 704-6.

28 Robinson R, O'Keefe $M$. Follow up study on premature infants with and without retinopathy of prematurity. $\mathrm{Br} \mathcal{F}$ Ophthalmol 1993; 77: 91-4. 